\title{
A high mountain population of the ring- tailed lemur Lemur catta on the Andringitra Massif, Madagascar
}

\author{
Steven M. Goodman and Olivier Langrand
}

The ring-tailed lemur Lemur catta is generally considered to be a species of dry deciduous forest, gallery forest and spiny thorn scrub at relatively low altitudes. During a survey of the summit zone of the Andringitra Massif, one of the most climatically extreme areas on Madagascar, we recorded this species above the treeline at $2520 \mathrm{~m}$ in an area composed mostly of exposed rock, low ericoid bush and subalpine vegetation. Information was collected on food plants consumed by this species. This pelage coloration of the local population of $\mathrm{L}$. catta differed from museum specimens and photographs taken from other areas of this species's range. The taxonomic status of the Andringitra population is in need of further study.

\section{Introduction}

Perhaps no species of lemur is better known scientifically than the ring-tailed lemur Lemur catta, which has been the subject of numerous ecological and behavioural studies. It is generally considered to be an animal of dry deciduous forest, gallery forest and spiny thorn scrub of southern and south-western Madagascar (Sussman, 1977; Tattersall, 1982; Harcourt and Thornback, 1990). In the literature on the distribution of Lemur catta there is mention of it occurring in 'interior highlands' (Tattersall, 1982: 46), 'one ... population occurs near the mountains of Andringitra on the southeastern plateau' (Mittermeier et al., 1994: 167), and 'it is found ... in the central-east to the Andringitra Massif' (our translation) (Petter $e t$ al., 1977: 157). Until we conducted a survey of the summit zone of the Andringitra Massif in early September 1995 little was known and published about this population.

\section{The north-eastern distribution limit of Lemur catta}

There is considerable ambiguity in the literature on the north-eastern limit of the range of
L. catta. This is in part due to the fact that many of the records refer to old specimens, and the range of this species may have been altered substantially over the past 100 years as a result of human-induced ecological changes. A project is very much needed to define precisely the distribution and ecological requirements of $L$. catta.

The most extreme north-eastern records appear to be near Ankafina $\left(21^{\circ} 13^{\prime} \mathrm{S}, 47^{\circ} 15^{\prime} \mathrm{E}\right.$; Jenkins, 1987) and $50 \mathrm{~km}$ west of Fianarantsoa on the Central High Plateau (Petter et al., 1977). The latter locality is approximately 90 $\mathrm{km}$ north-north-west of the Andringitra Massif (Figure 1). There were several observations of this species during 1993 and 1994 in the hills south and west of Ambalavao ( $P$. Schachenmann, pers. comm.), approximately half-way between Fianarantsoa and the Andringitra Massif. Sussman (1977) reported L. catta just south of Ambalavao along Route Nationale no. 7. This latter site is probably the forest just south of the village of Anapita (21 $\left.50.26^{\prime} \mathrm{S}, 46^{\circ} 50.55^{\prime} \mathrm{E}\right)$, at $920 \mathrm{~m}$ and $15 \mathrm{~km}$ west of Ambalavao, where we observed a group of eight $L$. catta on 25 January 1996. On 14 May 1993 at $1500 \mathrm{~m}$ and in the wooded foothills near Mahasoa $\left(21^{\circ} 59^{\prime} \mathrm{S}, 46^{\circ} 27^{\prime} \mathrm{E}\right)$, within a few $\mathrm{km}$ of the northern boundary of the Réserve

(C) $1996 \mathrm{FFI}$, Oryx $, 30(4), 259-268$ 


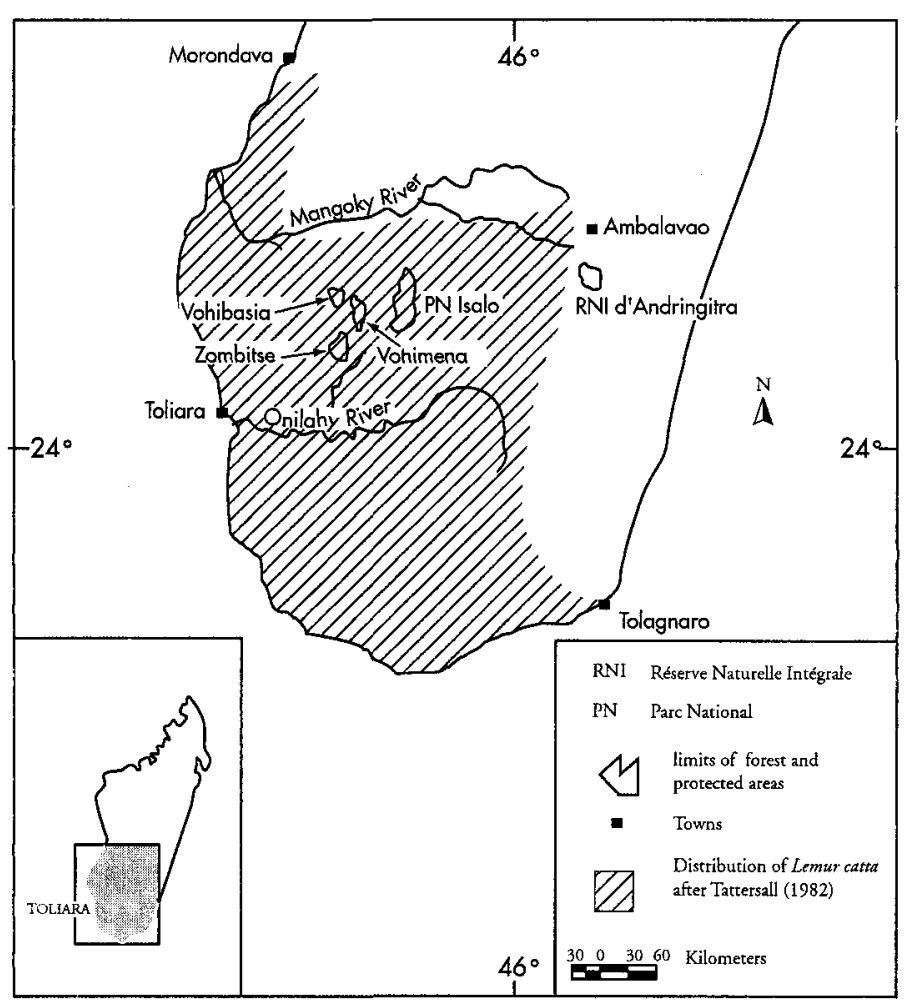

Figure 1. Geographical distribution of Lemur catta and main localities mentioned in the text.

Naturelle Intégrale (RNI) d'Andringitra, two groups of $L$. catta were heard vocalizing (O.L. and P. Schachenmann, pers. comm.). There are also recent observations in the high mountain zone of the massif to the west and north-west of the reserve in the vicinity of Morarano and Tsaranora (P. Schachenmann, pers. comm.). Specimens of $L$. catta were collected by the Franco-Anglo-Américaine Mission approximately $50 \mathrm{~km}$ south of the Andringitra Massif in the Réserve Spéciale d'Ivohibe (c. $22^{\circ} 31^{\prime} \mathrm{S}$, $46^{\circ} 59^{\prime} \mathrm{E}$; Buettner-Janusch and Tattersall, 1985; Jenkins, 1987; specimen in Muséum National d'Histoire Naturelle, Paris, C.G. 1932-3255). No altitude is given for the site where these specimens were obtained, but on the basis of the mission's report, collections were made in 'the forest country around Ivohibe' at 'about 800-1000 meters' (Rand, 1936). Further west of the Andringitra Massif there are numerous historical and recent records of this species in the Ihosy, Ranohira and Isalo region (Jenkins, 1987; pers. obs.). See Petter et al. (1977),
Sussman (1977) and Tattersall (1982) for reviews of this species's distribution.

\section{Description of the RNI d'Andringitra}

The RNI d'Andringitra has a surface area of $31,160 \mathrm{ha}$, within an elevational range of 650-2658 m, and contains botanical elements of the Eastern, Central and High Mountain domains (Nicoll and Langrand, 1989; Lewis $e t$ $a l .$, in press). The eastern slopes of the massif hold an extensive area of rain forest, the upper portion of which is largely sclerophyllous forest. Between 1900 and $2000 \mathrm{~m}$ the forest grades into a mosaic of ericoid bush and anthropogenic savannah and, towards the summit zone, into mixed ericoid and subalpine vegetation, and exposed rock. Below the summit zone are extensive plateau systems covered with altimontane meadows that have been modified by human disturbance, principally burning. The upper portions of the

(C) $1996 \mathrm{FFI}$, Oryx, 30 (4), 259-268 
Figure 2. Réserve Naturelle Intégrale d'Andringitra and localities mentioned in the text.

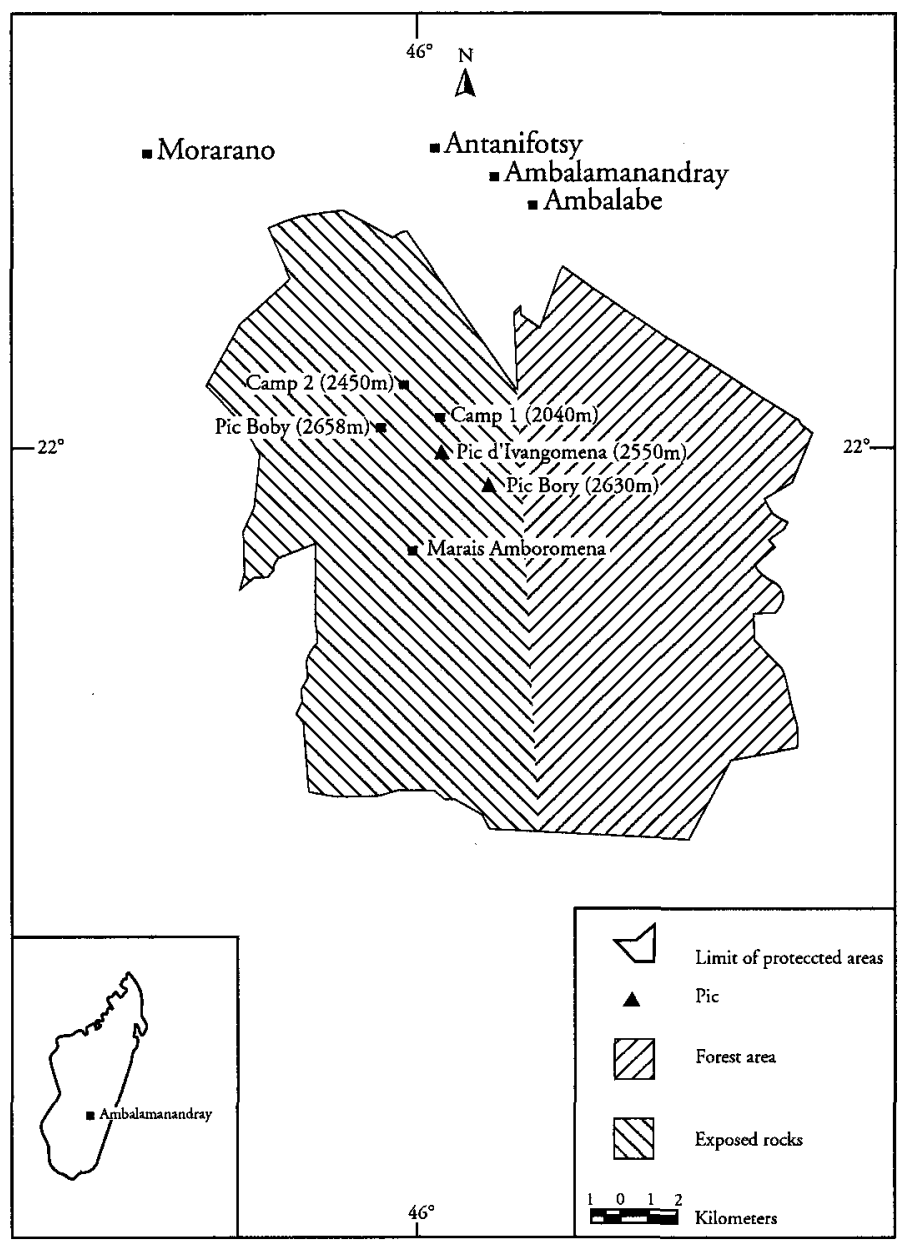

massif are extremely precipitous with deep eroded gullies and canyons.

In 1993 a biological inventory was conducted of the eastern slopes of the reserve, where 12 species of lemurs were recorded and no evidence was found of $L$. catta (Sterling and Ramaroson, in press). In September 1995 we returned to the reserve to complete the elevational transect of selected vertebrate groups. Two camps were established: 3-9 September along the Plateau d'Andohariana, 22 $11.52^{\prime} \mathrm{S}$, $46^{\circ} 54.27 \mathrm{E}, 2050 \mathrm{~m}$; and $9-15$ September in the Cuvette du Pic Boby, $22^{\circ} 10.89^{\prime} \mathrm{S}, 46^{\circ} 53.60^{\prime} \mathrm{E}$, $2450 \mathrm{~m}$ (Figure 2). The period of our visit coincided with the end of the cold season. Along the Plateau d'Andohariana daily minimum temperatures ranged from -2 to $+7^{\circ} \mathrm{C}$ (average $\left.=1.5^{\circ} \mathrm{C}, n=6\right)$ and maximum temperatures from 13 to $26^{\circ} \mathrm{C}$ (average $=19.5^{\circ} \mathrm{C}, n=6$ ) and in the Cuvette du Pic Boby daily minimum temperatures ranged from -7 to $+4^{\circ} \mathrm{C}$ (average $=-2.5^{\circ} \mathrm{C}, n=6$ ) and maximum temperatures from 16 to $26^{\circ} \mathrm{C}$ (average $=19^{\circ} \mathrm{C}, n=6$ ). On several mornings at the latter locality, stagnant or slow-running water was frozen to a depth sufficient to support the weight of a human. The months of June to August (generally the coldest months) often experience temperatures below freezing (Paulian et al., 1971). The high-mountain zone of the massif is considered to be the most frigid and meteorologically extreme site on the island, where over the past few decades snow has fallen on several occasions. 


\section{Information on the RNI d'Andringitra population of Lemur catta}

There are several records of $L$. catta on the Andringitra Massif. During his exploration of the Andringitra region in the early twentieth century, Perrier de la Bâthie (1927: 23) noted, 'the rocky areas of the western slope of the massif are inhabited by $L$. catta which occasionally occur up to the summits, and they climb with ease vertical rock walls' (our translation). Two Lemur catta were observed on 11 September 1941 at the pass below Pic Ivangomena (Anon., 1944). This is the same site where we found this species 54 years later (see below). It should be noted that the area around the summit is mostly composed of exposed rocks with sparse herbaceous and woody vegetation growing mostly in crevices. At this altitude bushes generally do not exceed $120 \mathrm{~cm}$ in height and trees are rare.

Petter et al. (1977: 157) based on a personal communication with J.M. Betsch, noted it [Lemur catta] lives on the Andringitra Massif within the ericoid bush, which does not exceed $2 \mathrm{~m}$ in height and forms a more or less continuous expanse of Ericaceae' (our translation). On 10 September 1995 a group of three individuals was observed at about $2600 \mathrm{~m}$ above the Marais d'Amboromena and on 11 September 1995 a group of four at $2600 \mathrm{~m}$ near Pic Bory (D. Popp, pers. comm.).

On 13 September 1995, between 15:30 and $17: 10 \mathrm{~h}$, we observed a group of $L$. catta at 2520 $m$ just below the vertical cliff of Pic Ivangomena $(2556 \mathrm{~m})$ at the pass along the trail between the Plateau d'Andohariana and Cuvette du Pic Boby (Figure 3). The group had reached the pass by climbing over an outcrop of huge bare rocks alternating with passages on vertical bare cliff faces virtually devoid of. vegetation. The ability of $L$. catta to scale vertical cliffs has been noted at several other localities (e.g. Parc National d'Isalo and the Forêt de Vohimena, north-east of Sakaraha, pers. obs.). The troop comprised eight individuals, including an adult female, which was leading the group and which was closely followed by an adult male. There were four other adults and two juveniles born the previous year.
After the group reached the pass, the lead female took a sentinel position on a vantage point for a few minutes before adopting, with the adult male, the typical sunning posture (Petter et al., 1977); during this period the rest of the troop began feeding. On the basis of scat remains found in the zone above $1900 \mathrm{~m}$, Cryptoprocta ferox, a known predator of $L$. catta (Goodman et al., 1993) is common at higher elevations in the RNI d'Andringitra, and perhaps the troop's vigilance was to counter attacks by this carnivore. Because nothing disturbed them, the adult female also started looking for food. Our observations of the troop feeding involved mainly the leading adult female and the closest adult male within $80 \mathrm{~m}$ of the observer. These two individuals were always vigilant, raising their heads every few seconds. Neither lemur spent much time foraging on individual plants, nibbling the tips of a few leaves before moving on to other plants.

When the adult female became aware of the observer, who was now within $50 \mathrm{~m}$ of the group, she and the adult male, made alarm calls. The typical yapping alarm call of these two individuals was repeated continuously until the observer retreated to a distance of about $100 \mathrm{~m}$. Immediately following the alarm calls, the six other individuals descended into the gorge and gave similar yapping calls from a vantage point on some exposed rocks. After the troop moved on, the lead female was observed scent-marking some bare rocks. No other species of lemur was recorded in the region surrounding the Cuvette du Pic Boby.

During the 13 days that we spent between 2050 and $2450 \mathrm{~m}$, we did not hear the characteristic territorial call of $L$. catta, which is normally emitted by males in the evening (Petter et al., 1977). We suspect that the reasons why no territorial call was heard is that the local population density of animals is very low because of the harsh environment and/or there is intensive pressure from local predators. However, an analysis of 30 Cryptoprocta scats collected in the area did not contain $L$. catta remains. A few local people in the nearby villages of Ambalamanandray and Antanifotsy mentioned that $L$. catta occurred on the 


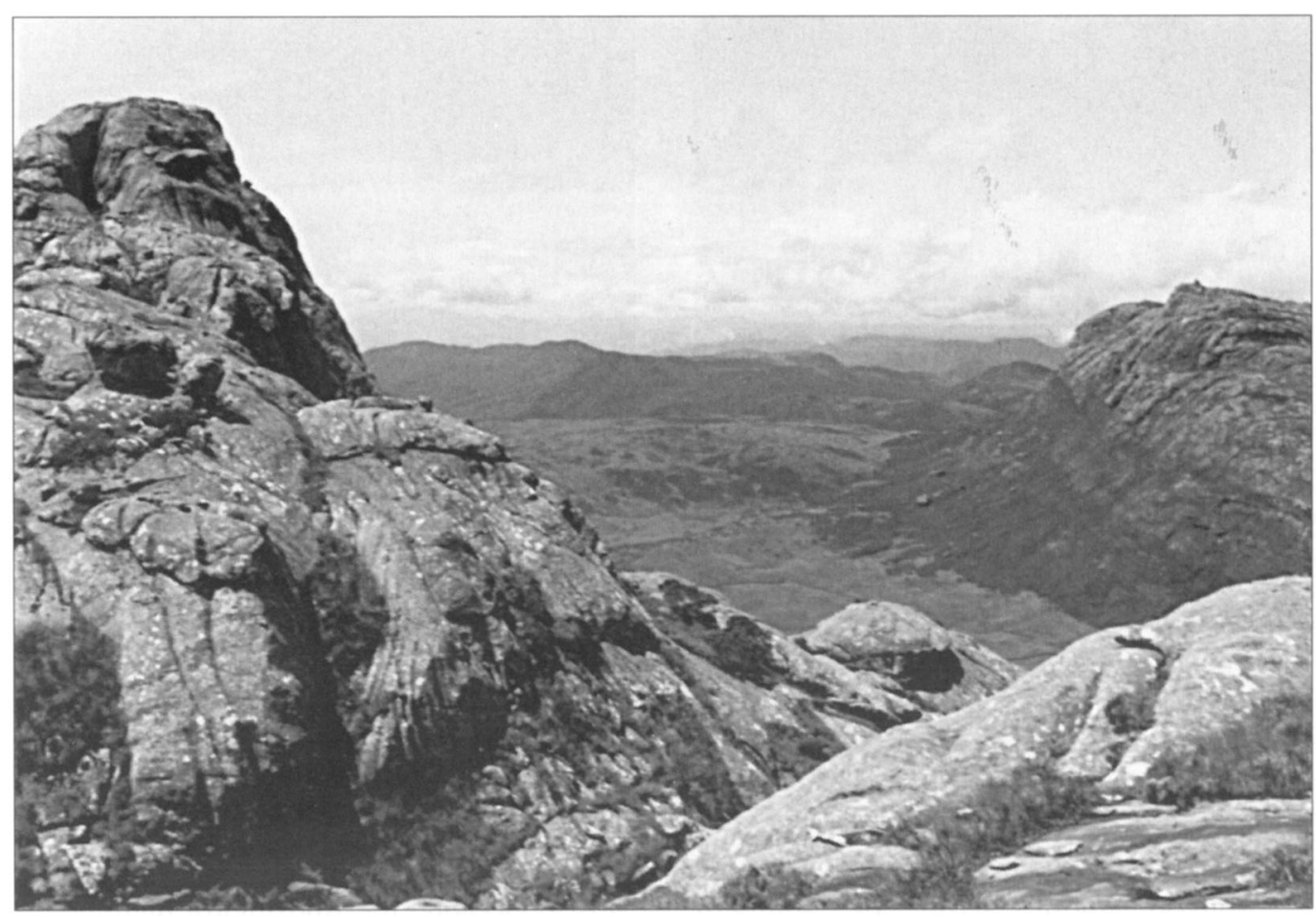

Figure 3. Summit zone of the Réserve Naturelle Intégrale d'Andringitra. The peak to the left is Ivangomena $(2556 \mathrm{~m})$ and the valley just below (lower centre) is the pass leading down to the Plateau d'Andohariana (distant centre). The troop of Lemur catta was observed scaling the upper portion of Pic Ivangomena (Olivier Langrand).

western slope of the massif, but they had few precise details. The personnel of the WWF Andringitra Project, who have been regularly visiting the western portion of the massif since 1993, have few records of this species. These statements are indicators of the low density of this species at high altitude.

Over the course of the 6 days we were camped in Cuvette du Pic Boby we noticed numerous plants that had been partially eaten by a herbivore. Subsequent analysis of Lemur catta dung and direct observation of the troop confirmed that these plants had been consumed by lemurs. The following plants were identified: Blechnum tabularae complex (Blechnaceae) - young fronds; Philippia spp. and Agauria salicifolia Hook. (Ericaceae) young leaves; Kalanchoe cf. bergeri Raym. Hamet \& H. Perrier, K. jongmansi Raym. Hamet \& H. Perrier and Sedum spp. (Family
Crassulaceae) - leaves and flowers; Senecio melastomaefolius Baker (Figure 4a), Helichrysum syncephaloides, and $H$. cf. otiphnocephalum (Asteraceae) - leaf tips and flowers; Anthospermum madagascariense Homolle ex Puff (Rubiaceae) - leaf tips; and Aloe andringitrensis H. Perrier (Aloeaceae) - succulent leaves (Figure $4 \mathrm{~b}$ ). The nibbling pattern of Lemur catta on leaves is distinctive and easy to recognize. On this basis, we found feeding evidence of $L$. catta in a large area around the Cuvette du Pic Boby from 2500 up to $2630 \mathrm{~m}$. Perrier de la Bâthie (1927: 23) noted that 'they eat the leaves of succulent plants (Aloe and Kalanchoe), herbs, seeds and tubers, and have completely abandoned their arboreal habits' (our translation). Although three other species of Aloe are known from the Andringitra Massif (Reynolds, 1958; Paulian et al., 1971; Lewis et al., in press), we found evidence only 

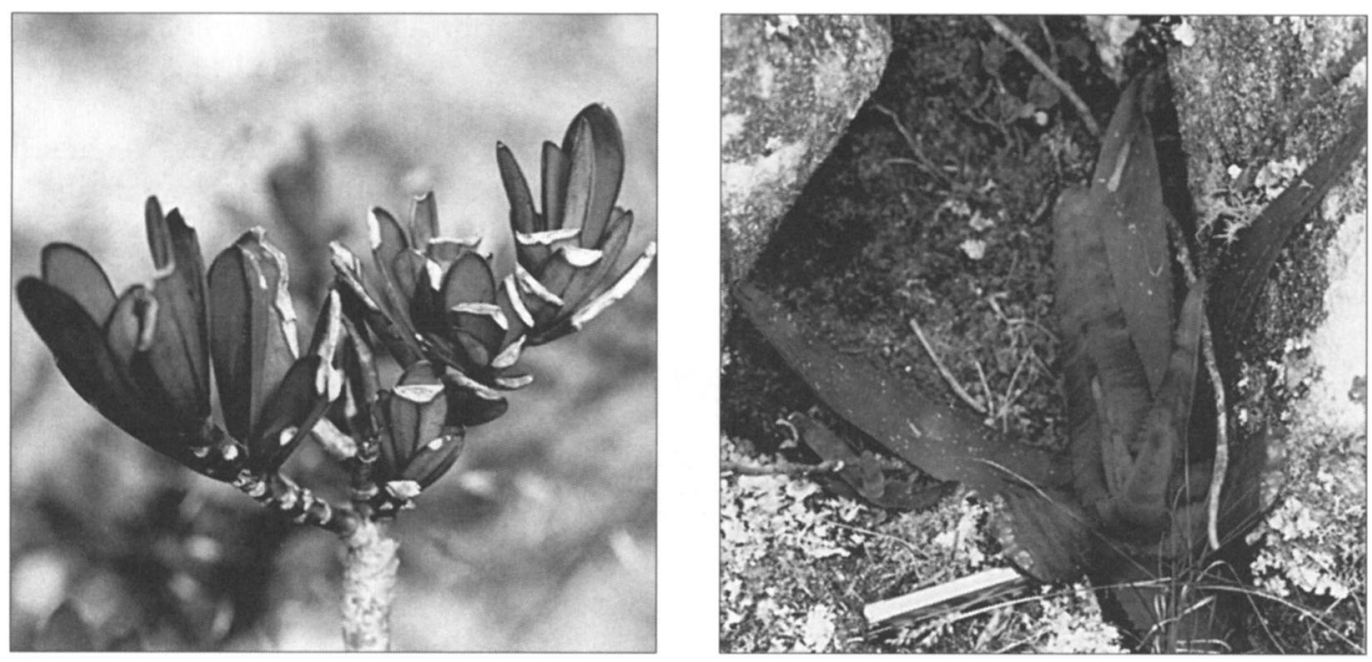

Figures $4 \mathbf{a}$ and $\mathbf{b}$. Lemur catta food plants on the upper slopes of the Réserve Naturelle Intégrale d'Andringitra, including ( $a$, left) Senecio melastomaefolius Baker with clearly nibbled leaves and, (b, right) Aloe andringitrensis $\mathrm{H}$. Perrier with recent gnawing marks on remains of leaf next to pocket knife (Olivier Langrand).

of $A$. andringitrensis being consumed by Lemur. In subarid thorn scrub of southern Madagascar $L$. catta is known to eat Agavaceae and Aloeaceae, specifically Agave rigida (introduced) and Aloe vaombe, as well as Kalanchoe beharensis (Crassulaceae) and Xerosicyos perrieri (Cucurbitaceae; Budnitz and Dainis, 1975; O'Connor, 1987). Consumption of these plants may be generally restricted to periods of low food and water availability (M. Pidgeon, pers. comm.).

The local population of $L$. catta may move up and down the mountain on a seasonal basis, which would explain the occasional observations of this species at the upper reaches of the massif. M. Ramosa, an inhabitant of Ambalabe, a village at the reserve limit, is of the opinion that there are regular seasonal movements between the east and west portions of the massif, which depend on temperature and the availability of food plants.

\section{Pelage coloration and taxonomic status}

Members of the single troop of Lemur catta that we observed in the RNI d'Andringitra were distinctly different in pelage coloration and texture from typical individuals from other portions of this species's range (Table 1). Most noticeably, the Andringitra high-mountain population has a consistently darker and more rufous brown back (Plate $1 a$ and $b$ ) compared with the typical dorsal colour of $L$. catta, which has been described as warm rosy brown (Tattersall, 1982) and pearl grey (Haltenorth and Diller, 1977; Petter et al., 1977). Further, the Andringitra animals have distinctly thicker pelage, giving them a woolly appearance, and have fewer black-and-white tail rings than typical catta. Given that several authors have noted $L$. catta shows little variation in pelage colour and tail-banding pattern throughout its range (Petter et al., 1977: 142; Tattersall, 1982: 45), these differences are particularly noteworthy.

Photographs of Andringitra L. catta have been compared with specimens in the Muséum National d'Histoire Naturelle, Paris, and the Parc Botanique et Zoologique de Tsimbazaza, Antananarivo, and published photographs taken at numerous sites across the range of this species. In no case did we find an adult $L$. catta that possessed the richly saturated dorsal colour or thick pelage of the Andringitra population. The $L$. catta population living in the forest of Anapita, just west of Ambalavao 

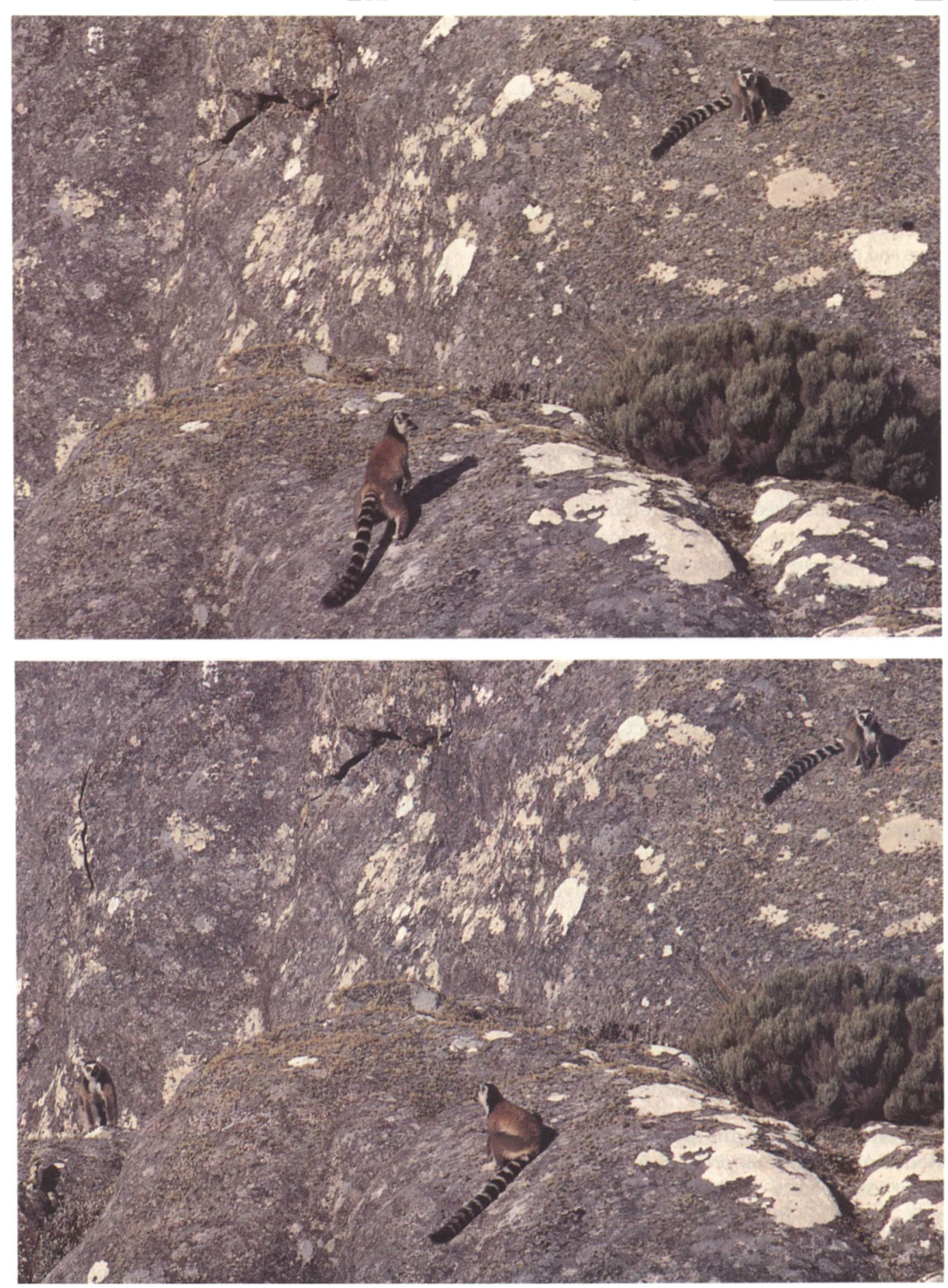

Plate 1a and b. Portion of a troop of eight Lemur catta found at $2520 \mathrm{~m}$ in the Réserve Naturelle Intégrale $\mathrm{d}^{\prime}$ Andringitra. The pelage coloration and pilosity of this population differs from typical $L$. catta (Olivier Langrand). 


\begin{tabular}{|c|c|c|}
\hline Pelage area & $\begin{array}{l}\text { Andringitra } \\
\text { population }\end{array}$ & $\begin{array}{l}\text { Typical adult } \\
\text { L. catta* }\end{array}$ \\
\hline Dorsum & Dark rufous brown & Warm rosy brown \\
\hline Rump & Dark brown & Light grey or grey-brown \\
\hline Limbs & Dark grey-brown & Light grey or grey-brown \\
\hline Ventrum & White & White or cream \\
\hline Black tail rings & $11-12$ & $13-14$ \\
\hline White tail rings & $10-11$ & $12-13$ \\
\hline Ears and throat & White & White \\
\hline Orbital ring & Black & Dark grey or black \\
\hline
\end{tabular}

Table 1. Comparison of pelage coloration of Lemur catta on the Andringitra Massif and other areas of this species's range in southern Madagascar

*Based on Tattersall (1982).

and within $40 \mathrm{~km}$ of Pic Boby, possesses the dorsal pelage coloration and tail pattern typical of this species throughout its range. Thus it appears that the population displaying the phenotype observed in the high-mountain zone of the Andringitra Massif is very localized.

On the basis of fragmentary information available about the pelage coloration of $L$. catta inhabiting the upper elevations of the Andringitra Massif, it appears to be a well-differentiated and isolated population. Whether this population represents a geographic variant of typical catta or a distinct undescribed species of Lemur (sensu Simons and Rumpler, 1988) remains to be determined. We refrain from any definitive taxonomic conclusions until specimen material of the Andringitra population is available and subsequent morphological and biochemical studies have been conducted. If the population is indeed an undescribed form, we recommend that the describers take the necessary measures to place a holotype specimen in a museum collection.

\section{Conservation considerations}

The ericoid zone of the upper slopes of the RNI d'Andringitra is prone to bush fires. The plant community is dominated by Philippia spp., which are highly flammable, and natural climatic factors (e.g. wind and a long dry season) make conditions favourable for the spread of fire. Formerly this vegetation was ignited by lightning, but since human colonization of the area the frequency and extensiveness of fires have increased. Despite the legal protection of the reserve since its creation in 1927 (Nicoll and Langrand, 1989), fires are set at least in part to stimulate growth of new grassland for cattle (Salomon, in press). Most areas of the western slope of the RNI d'Andringitra, including Pic Boby, have been burned over the past few decades. Fires started by humans were recorded in the area by some early western explorers (e.g. Humbert, 1927; Perrier de la Bâthie, 1927) In 1986, 1990 and 1995 major fires occurred in the north-western sector of the reserve (pers. obs.).

It is likely that the high mountain population of $L$. catta within the RNI d'Andringitra is affected by fire, which spreads rapidly, with intense heat, across the ericoid zone. Animals caught in the middle of such a fire would presumably perish. Such burning affects the area above $2000 \mathrm{~m}$, particularly the slopes below the summit, which are covered with Philippia spp. and Agauria spp. Even though Agauria trees are fire resistant and even at high altitudes can reach considerable size (Berner, in press), they are becoming rarer, presumably due to the unnatural frequency of human-induced fires. This may affect the population of L. catta, which apparently relies on this tree for food.

Lemur catta is known from six existing protected areas and the future national park of Zombitse-Vohibasia (Nicoll and Langrand, 1989; Mittermeier et al., 1992). It is not known to show any variation in pelage colour or pilosity at these sites. If the Lemur population found in the RNI d'Andringitra turns out to 
be phenotypically and genetically distinct, the importance of the reserve will increase. Further, with 13 species of lemur, the RNI $\mathrm{d}^{\prime}$ Andringitra holds the greatest primate diversity of any known reserve on the island (Mittermeier et al., 1992). We would recommend that future activities linked with the management of the reserve include: (i) surveys to identify the local distribution, ecology and population size of $L$. catta; and (ii) development of a system to control fires.

\section{Acknowledgements}

Our research in Madagascar has been authorized by the Association Nationale pour la Gestion des Aires Protégées, Direction des Eaux et Forêts and the Commission Tripartite. We are particularly thankful to Chantal Andrianarivo, Henri Finaona, Faramalala Miadana and Célestine Ravaoarinoromanga for issuing permits; France Rakotondrainibe, Coca Rakotomalaza and Andréas Bosshard for plant identifications; and Pierre Berner, Mark Pidgeon, Dieter Popp and Peter Schachenmann for unpublished observations. Curators at the Muséum National d'Histoire Naturelle, Paris, and Parc Botanique et Zoologique Tsimbazaza, Antananarivo, provided access to comparative material under their care. Hanta Rabetaliana, Rogez Ramanatsoa, Sylvain Razafimandimby and Peter Schachenmann of WWF facilitated our work within the reserve. For comments on an earlier version of this paper we are grateful to Mark Pidgeon, Peter Schachenmann, Robert Sussman and an anonymous referee.

\section{References}

Anon. 1944. Le Massif de l'Andringitra. Revue de Madagascar, 2 (13), 27-45.

Berner, P.O. In press. La conservation des forêts de montagnes de la partie nord-est des massifs rocheux de 1'Andringitra, Madagascar. Akon'ny Ala.

Budnitz, N. and Dainis, K. 1975. Lemur catta: ecology and behaviour. In Lemur Biology (eds I. Tattersall and R. W. Sussman), pp. 219-235. Plenum Press, New York.

Buettner-Janusch, J. and Tattersall, I. 1985. An annotated catalogue of Malagasy primates (Families Lemuridae, Indriiidae, Daubentoniidae, Megaladapidae, Cheirogaleidae) in the collections of the American Museum of Natural History. Am. Mus. Nov., 2834, 1-45.

Goodman, S.M., O'Connor, S. and Langrand, O. 1993. A review of predation on lemurs: implica- tions for the evolution of social behaviour in small, nocturnal primates. In Lemur Social Systems and their Ecological Basis (eds P. M. Kappeler and J. U. Ganzhorn), pp. 51-66. Plenum Press, New York.

Haltenorth T. and Diller, H. 1977. Mammiferes d'Afrique et de Madagascar. Delachaux et Niestlé, Neuchâtel.

Harcourt, C. and Thornback, J. 1990. Lemurs of Madagascar and the Comoros. The IUCN Red Data Book. IUCN-The World Conservation Union, Gland and Cambridge.

Humbert, H. 1927. Le destruction d'une flore insulaire par le feu. Principaux aspects de la végétation à Madagascar. Mémoires de l'Académie Malgache, 5, 1-79.

Jenkins, P.D. 1987. Catalogue of Primates in the British Museum (Natural History) and elsewhere in the British Isles. Part IV: Suborder Strepsirrhini, including the subfossil Madagascan Lemurs and the Family Tarsiidae. British Museum (Natural History), London.

Lewis B.A., Phillipson, P.B., Andrianarisata, M. Rahajasoa, G., Rakotomalaza, P.J., Randriambololona, M. and McDonagh, J.F. In press. A study of the botanical structure, composition and diversity of the eastern slopes of the Réserve Naturelle Intégrale d'Andringitra, Madagascar. In A Fauna and Flora Survey of the Eastern Side of the Réserve Naturelle Intégrale d'Andringitra, Madagascar, with particular reference to elevational variation (ed. S. M. Goodman). Fieldiana: Zoology. New series No. 127.

Mittermeier, R.A., Konstant, W.R., Nicoll, M.E. and Langrand, O. 1992. Lemurs of Madagascar. An Action Plan for their Conservation. 1993-1999. IUCN/SCC Primate Specialist Group, Gland.

Mittermeier, R.A., Tattersall, I., Konstant, W.R., Meyers, D.M. and Mast, R.B. 1994. Lemurs of Madagascar. Conservation International, Washington, DC.

Nicoll, M.E. and Langrand, O. 1989. Madagascar: Revue de la conservation et des aires protégées. World Wide Fund for Nature, Gland.

O'Connor, S.M. 1987. The effect of human impact on vegetation and the consequences to primates in two riverine forests, southern Madagascar. PhD thesis, University of Cambridge, Cambridge.

Paulian, R., Betsch, J.M., Guillaumet, J.L., Blanc, C. and Griveaud, P. 1971. RCP 225. Etudes des écosystèmes montagnards dans le région malgache. I. Le massif de l'Andringitra. 1970-1971. Géomorphologie, climatologie et groupements végétaux. Bulletin de la Société d'Ecologie, II (2-3), 198-226.

Perrier de la Bâthie, H. 1927. Le Tsaratanana, l'Ankaratra et l'Andringitra. Mémoires de Académie Malgache, 3, 1-71. 
Petter, J-J., Albignac, R. and Rumpler, Y. 1977. Mammifères Lémuriens (Primates Prosimiens). Faune de Madagascar 44, ORSTOM and CNRS, Paris.

Rand, A.L. 1936. Distribution and habits of Madagascar birds. Bull. Amer. Mus. Nat. Hist., 72, 143-499.

Reynolds, G.W. 1958. Les Aloes de Madagascar. Le Naturaliste Malgache, 10, 1-156.

Salomon, J.N. In press. La deforestationMadagascar à une dynamique inquiétante.

Sterling, E.S. and Ramaroson, M.G. In press. Rapid assessment of the primate fauna of the eastern slopes of the Réserve Naturelle Intégrale d'Andringitra, Madagascar. In A Fauna and Flora Survey of the Eastern Side of the Réserve Naturelle Intégrale d'Andringitra, Madagascar with Particular Reference to Elevational Variation. (ed. S. M. Goodman). Fieldiana: Zoology, New series No. 127.

Simons, E.L. and Rumpler, Y. 1988. Eulemur: new generic name for species of Lemur other than
Lemur catta. C.R. Acad. Science Paris, ser. 3, 307, 547-551.

Sussman, R.W. 1977. Distributions of the Malagasy lemurs Part 2: Lemur catta and Lemur fulvus in southern and western Madagascar. Annals New York Acad. Sci. 293, 170-184.

Tattersall, I. 1982. The Primates of Madagascar. Columbia University Press, New York.

White, F. 1983. The Vegetation of Africa. A Descriptive Memoir to Accompany the UNESCO/AETFAT/ UNSO Vegetation Map of Africa. Natural Resources Research 20, UNESCO, Paris.

Steven M. Goodman, World Wide Fund for Nature, BP 738, Antananarivo (101), Madagascar and Field Museum of Natural History, Roosevelt Road at Lake Shore Drive, Chicago, Illinois 60605, USA.

Olivier Langrand, World Wide Fund for Nature, BP 738, Antananarivo (101), Madagascar. 